\title{
UTILITY OF SALIVARY CA-125 AND LDH AS A TUMOR MARKER IN ORAL MALIGNANCY
}

\author{
Yadav Shweta, Deherkar JA, Sangle AR, Chandorkar SS. \\ Department of General Surgery, \\ Bharati Vidyapeeth Hospital and Research Centre, Pune, Maharashtra, India.
}

\section{ABSTRACT}

Background: The mortality and morbidity associated with oral Squamous cell carcinoma (OSCC) can be greatly reduced if tumor markers which can detect OSCC at an early stage are available. This study attempts to use saliva as the diagnostic medium to determine the correlation of salivary CA 125 and LDH in tobacco users with and without potentially malignant disorders. Changes in CA 125 and LDH level can be used as a marker in patients with and without premalignant disease and can be used as a deterrent in continuation of the habit. Aims: To assess the role of CA $125 \&$ LDH as a tumour marker in Oral cancer patients. Materials and methods: Cross sectional observational study .Time period: December 2015 to August 2017.Study area: OPD of tertiary care hospital in pune. Total participants: 150 persons. Under non-stimulatory conditions whole saliva sample was collected from each individual and was centrifuged. The resulting supernatant was used for estimation of CA 125 and LDH levels. Results: In present study, mean Salivary LDH level was found to be lowest among cases of healthy individuals while it was highest among individuals who were diagnosed and underwent treatment for malignancy. However there was insignificant difference seen between levels of diagnosed case of oral malignancy and the ones who underwent treatment for oral malignancy. Also mean Salivary CA-125 was lowest in healthy individuals and highest in individuals diagnosed with oral malignancy and the levels were seen to be reduced significantly in the one who underwent treatment for oral malignancies than those who didn't. Conclusion: Salivary CA 125 and LDH has a role in early detection of oral malignancies and can be used as a diagnostic marker. However LDH levels are persistently raised even after treatment for oral malignancy.

KEYWORDS: Oral squamous cell carcinoma; Tumour markers; Salivary CA125; LDH.

\section{INTRODUCTION}

Oral cancer refers to all malignancies arising from the lips, alveolus, floor of mouth, cheek, tongue, gingiva and pharynx [1]. It is one of the major global public health problems and is the sixth most common human malignancy with a five year mortality rate of almost $50 \%$ [2]. This has not changed significantly over the last 50 years [3].It is the commonest cancer in males and the third commonest cancer in females in India. More than $90 \%$ of tumours of the oral cavity are squamous cell carcinoma arising from the oral mucosa [4]. Squamous cell carcinoma occurs mostly in men aged 45 years and older and is associated with tobacco and alcohol consumption [5].A high prevalence of oral cancer

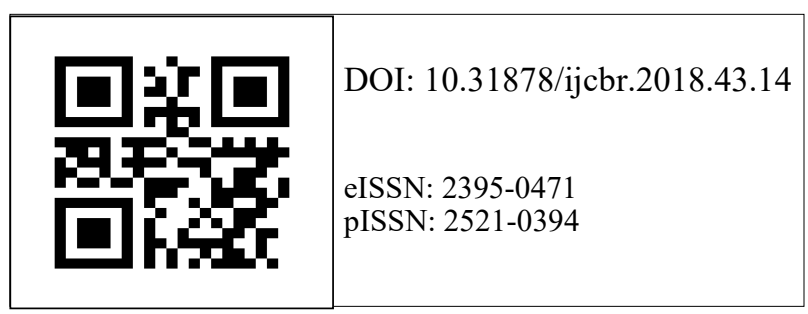

in India and other Asian countries has been attributed to the influence of region specific epidemiological factors such as tobacco and betel quid chewing[6]. Oral cancer is a major problem in the Indian subcontinent where it ranks among the top three types of cancer in the country [7].

Age-adjusted rates of oral cancer in India is high i.e. 20 per 100,000 population and accounts for over $30 \%$ of all cancers in the country [8]. Another alarming scenario is the increasing incidence of oral squamous cell carcinoma (OSCC) in younger people owing to the heavy abuse of alcohol, tobacco and tobacco related products. Even though clinical diagnosis occurs via examination of the oral cavity and tongue which is easily accessible by current diagnostic tools, the majority of cases present to a healthcare facility at later stages of cancer, thereby reducing chances of survival due to delay in diagnosis [9].

Tumour markers are substances present in, or produced by, a tumour itself or produced by a host in response to a tumour that can be used to differentiate a tumour from normal tissue or to determine the pres-

Correspondence: Dr. Shweta Yadav, A-504, New PG hostel, Bharati Vidyapeeth Hospital, Katraj, Satara Road, Pune, Maharashtra, India. Email: shwetacardiosurgeon@gmail.com 
ence of a tumour based on measurements in blood or secretions $[10,11]$. Tumour markers include various substances like cell surface antigens, cytoplasmic proteins, enzymes, hormones, oncofetal antigens, receptors, oncogenes and their products [10]. These substances can be found in blood, saliva, urine, stool, tumour tissue, or other tissues or bodily fluids of patients with cancer.

Tumour markers are very useful in monitoring the course of a diagnosed malignant tumour, for example their levels decrease in response to treatment and increase when the cancer recurres or is irresponsive to any treatment modality. When used in combination with other investigations the changed levels of tumour markers can be extremely useful in the detection and diagnosis of cancer [12]. Currently biopsy is considered to be a gold standard diagnostic technique for diagnosing oral malignancy.

The purpose of this study was to assess that salivary CA -125 and LDH can be used as a potential tumour markersfor early diagnosis and treatment of OSCC.

Aim:-To assess the role of CA $125 \&$ LDH as a tumour marker in Oral cancer patients.

Objectives:- 1) To estimate the levels of salivary CA 125 and $\mathrm{LDH}$ in following groups

\section{MATERIALS AND METHODS}

Study design: cross sectional observational study.

Ethics approval: This study was approved by the ethical committee of our institute

Study Period: December 2015 to August 2017.

Study location: Bharati Hospital, Pune. (Tertiary care centre)

Study population: 90 random patient presenting with oral pathology, 30 individuals addicted to tobacco.

And 30 individuals who are in good health without any addiction.

Inclusion criteria: All patients above 18 years, attending Bharati hospital surgery OPD for Oral pathology were included in this study

Exclusion criteria: Patients with a history of any other malignancy. Subjects with psychiatric disorders who can't give consent.

Grouping: Group 1: 30 absolutely healthy individuals with no habit of tobacco chewing, smoking and alcohol.

Group 2: 30 healthy tobacco users and smokers without apparent clinical oral lesion.

Group 3: 30 patients with proven Pre malignant lesions in oral cavity.

Group 4: 30 diagnosed case of oral cancers for the first time.

Group 5: 30 patients who have undergone surgery and coming for regular follow up and are in 3rd month after surgery.

\section{Methodology}

Under non-stimulatory conditions 5cc whole saliva sample was collected from each individual of all the groups in a wide mouth container. Saliva sample was immediately centrifuged at $3000 \mathrm{rpm}$ for 10 minutes to remove squamous cells and debris. The resulting supernatant fluid was subjected to ELISA for assessment of CA 125 and LDH levels. [13]

Statistical analysis: The collected data was coded and entered in Microsoft Excel sheet. Mean, SD and Median was calculated for quantitative data. Salivary concentrations of CA125 in normal, premalignant lesion and oral squamous cell carcinoma patients were compared using Mann-Whitney $U$ test.

\section{RESULTS}

The study covered total of 150 subjects divided into 5 groups. Salivary sample was collected from each of these individuals to assess the level of CA -125 and LDH. Advantages of salivary sample collection were that it was noninvasive, easy, safe and inexpensive. The sample collection did not require any trained medical staff. It could be collected anywhere. Also, it was easy to store and transport to the laboratory.

Of these $71 \%$ were males and $29 \%$ were females.Overall higher male prevalence was seen among cases with pre- malignant and malignant oral cavity lesions.

The mean age of the cases with pre-malignant and malignant oral cavity lesions was 51.73 years and 55.87 years respectively.

Also mean Salivary CA-125 was lowest in group 1 and highest in group 4 and the levels were seen to be reduced significantly in group 5 as compared to group 4 . (Table 1)

In present study, mean Salivary LDH level was found to be lowest among cases of group1 while it was highest among cases of group 5. However there was insignificant difference seen between levels of group 4 and group 5. (Table 2)

Table 1. Comparison of mean salivary CA-125 levels among study groups.

\begin{tabular}{|c|c|c|c|}
\hline Variables & Group & Mean \pm SD & $p$-value \\
\hline \multirow{5}{*}{$\begin{array}{l}\text { Salivary- } \\
\text { CA-125 } \\
\text { (mg/dl) }\end{array}$} & 1 & $\begin{array}{l}33.00 \pm 24 . \\
37\end{array}$ & \multirow{5}{*}{$\begin{array}{l}\text { Total } p-\text { value } \\
\text { in all the groups } \\
\text { was }<0.01 \\
\text { (Group1 vs } \\
\text { group 2,3,4 } 5 \\
\text { Group } 2 \text { vs } \\
\text { group3,4,5 } \\
\text { Group } 3 \\
\text { group 4,5 } \\
\text { Group } 4 \text { vs } \\
\text { group 5) }\end{array}$} \\
\hline & 2 & $\begin{array}{l}296.67 \pm 1 \\
61.4\end{array}$ & \\
\hline & 3 & $\begin{array}{l}809.64 \pm 5 \\
61.7\end{array}$ & \\
\hline & 4 & $\begin{array}{l}1362.19 \pm \\
523.3\end{array}$ & \\
\hline & 5 & $\begin{array}{l}888.15 \pm 3 \\
06.1\end{array}$ & \\
\hline
\end{tabular}


Table 2. Comparison of mean salivary LDH levels among study groups.

\begin{tabular}{|c|c|c|c|}
\hline Variables & Group & Mean & $p$-value \\
\hline \multirow{5}{*}{$\begin{array}{l}\text { Salivary } \\
\text { LDH } \\
\text { (mg/dl) }\end{array}$} & 1 & $\begin{array}{l}63.04 \pm \\
47.4\end{array}$ & \multirow{3}{*}{ 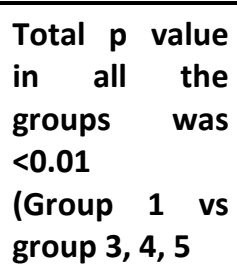 } \\
\hline & 2 & $\begin{array}{l}231.67 \pm 1 \\
96.44\end{array}$ & \\
\hline & 3 & $\begin{array}{l}786.23 \pm 4 \\
32.67\end{array}$ & \\
\hline & 4 & $\begin{array}{l}1515.17 \pm \\
765.14 \\
\end{array}$ & $\begin{array}{l}\text { Group } 2 \text { vs } \\
\text { group } 3,4,5\end{array}$ \\
\hline & 5 & $\begin{array}{l}1518.13 \pm \\
1315.99\end{array}$ & $\begin{array}{ll}\text { Group } \quad 3 & \text { vs } \\
\text { group 4, 5) } & \end{array}$ \\
\hline
\end{tabular}

\section{DISCUSSION}

Oral cancer, when found early, has an 80 to $90 \%$ survival rate. Despite this fact and great treatment advances, the World Health Organization has reported oral cancer as having one of the highest mortality ratios amongst other malignancies with a death rate at five years from diagnosis (45\%) [14]. This high morbidity rate can definitely be attributed to the late diagnosis of the disease [15].

Tumour markers are very useful in monitoring the course of a diagnosed malignant tumour, for example pre-treatment and subsequent serial values are essential for the evaluation of the response to the treatment modality with time. When used in combination with biopsies and other tests the detection of tumour markers in the blood can be extremely useful in the early detection of cancer thereby significantly improving its prognosis[12] .

The present study was thus conducted to assess the role of Salivary CA 125 \& LDH as a tumour marker in Oral Cavity cancer. The study included total of 150 subjects, 30 each groups as mentioned earlier in Table 1. and 2.

$\mathrm{LDH}$ represents a marker to cell death and tissue breakdown and its raised level often signifies a disease process [16]. CA125 is a repeating peptide epitope of the mucin MUC16 $[17,18]$, which promotes cancer cell proliferation and inhibits anti-cancer immune responses [19-22]. CA125 has been extensively investigated as a biomarker in three separate clinical scenarios as a screening test for the early detection of cancer, to distinguish between benign and malignant disease and to monitor response to therapy.

In present study, overall higher male prevalence was seen among cases with pre-malignant (group3) and malignant (group4) oral cavity lesions whereas there are studies having the highest incidence of oral cancer in the world with significant male preponderance[23] just like ours.
The mean age of the cases with pre-malignant (group3) and malignant (group4) oral cavity lesions in this study was 51.73 years and 55.87 years respectively. Aggarwal R et al.[24] in their study of total 133 cases found mean of 50.16 years. Similar results were also reported by Pudasaini $S$ et al. [25]with mean age of 51.6 years. Similar results were also observed by other authors [26,27].

In our study, mean Salivary LDH level was lowest among controls(group1) $(63.04 \mathrm{mg} / \mathrm{dl})$ while it is highest among cases of oral carcinoma after treatment (group5)(1518mg/dl )also there was insignificant difference among cases of carcinoma before (group4)(1515 $\mathrm{mg} / \mathrm{dl}$ ) and after treatment (group5)(1518.13 mg/dl). LDH Levels were able to differentiate between cases with pre malignant lesions (group3) $(786.23 \mathrm{mg} / \mathrm{dl})$ and healthy controls (group1) $(63.04 \mathrm{mg} / \mathrm{dl})$. Also, significant difference was noted between healthy controls (group1) $(63.04 \mathrm{mg} / \mathrm{dl}$ ) and healthy tobacco users (group2) $(231.67 \mathrm{mg} / \mathrm{dl}$ ). A similar study was conducted by Shpitzer et al.[28] and it was found that salivary LDH was significantly higher in the patients with OSCC compared to the control group ( $p<0.05)$. Nagler et al.[29] in their study observed raised level in both pre-malignant and malignant oral mucosa pathologies. Joshi et al.[30] in their study observed the mean lactate level in control, pre-malignant and OSCC group as $267.2 \mathrm{IU} / \mathrm{L}$, $519.36 \mathrm{IU} / \mathrm{L}$ and $788.73 \mathrm{IU} / \mathrm{L}$ respectively $(\mathrm{p}<0.01)$. Shpitzer et al.[28] and Shpitzer et al.[31] also found total salivary LDH levels to be high in oral cancer patients. Our results are also comparable with the study done by Shetty et al.[32] who have reported consistently higher salivary LDH levels in oral precancer and cancer patients as compared to healthy controls.

In this study, mean Salivary CA-125 level was very well able to distinguish between control (group1), premalignant (group3) and malignant lesions (group4) with lowest values seen among controls (group1) $(33.0 \mathrm{mg} / \mathrm{dl}$ ) followed by healthy tobacco users (group2) (296.67 $\mathrm{mg} / \mathrm{dl}$ ), cases with pre malignant lesions (group3) $(809.64 \mathrm{mg} / \mathrm{dl})$ and it was highest among cases of oral carcinoma (group4) $(1362.2 \mathrm{mg} / \mathrm{dl})$. Also the levels salivary CA-125 were seen to be reduced significantly postoperatively in patients of group $5(888.15 \mathrm{mg} / \mathrm{dl})$ as compared to patients with oral malignancy in group 4 (1362.2 mg/dl) Balan et al.[13] in a similar study observed the mean salivary CA 125 values of OSCC patients as 320.25 and that of control group as 33.14 $(p<0.05)$. Rihan $M$ et al. [33], observed the level of salivary CA-125 as $342.65 \mathrm{U} / \mathrm{ml}$ in cases of OSCC which was significantly increased compared with $203.65 \mathrm{U} / \mathrm{ml}$ in the healthy controls, (P 0.017). The authors concluded that salivary CA-125 can be a potential tumor marker for OSCC. Geng XF et al. [34] in their study also observed significant difference in CA-125 levels among patients with OSCC than in patients with non-neoplastic disease and healthy controls, however contrary to our findings CA-125 levels were not significantly different 
between patients with non-neoplastic disease and controls.

\section{CONCLUSION}

These observations showed that salivary CA 125 and $\mathrm{LDH}$ has a role in early detection of oral malignancies and differentiating between premalignant and malignant lesions. The present study was done in a limited population, thus needs further evaluation in larger cohort studies to see the role of high CA-125 and LDH level among tobacco chewers and its prognostic value in cases who quit or continued tobacco chewing and developed OSCC.

\section{REFERENCES}

1. World Health Organization. The ICD-10 classification of mental andbehavioural disorders: clinical descriptions and diagnostic guidelines. World Health Organization; 2010;10(2):97.

2. Ferlay J, Shin HR, Bray F, Forman D, Mathers C, Parkin DM.GLOBOCAN 2008, cancer incidence and mortality worldwide: IARCCancer Base No. 10 [Internet]. Lyon, France: International Agency for Research on Cancer. 2010:5-6.

3. Sparano A, Weinstein G, Chalian A, Yodul M, Weber R. Multivariatepredictors of occult neck metastasis in early oral tongue cancer.Otolaryngol Head Neck Surg. 2004;131:472-6.

4. P.K Tsantoulis, N.G. Kastrinakis, A.D Tourvas, G. Laskaris, V.SGorgoulis. Advances in the biology of oral cancers. 2007;43:523-534.

5. Community Dent Oral Epidemiology, WHO guest editorial2005;33:397-399.

6. Tsantoulis PK, Kastrinakis NG, Tourvas AD, Laskaris $\mathrm{G}$, Gorgoulis VG.Advances in the biology of Oral cancer. 2007;43:523-34.

7. Elango JK, Gangadharan P, Sumithra S, Kuriakose MA. Trends of headand neck cancers in urban and rural India. Asian Pacific Journal ofCancer Prevention. 2006;7(1):108-112.

8. Sankaranarayanan R, Ramadas K, Thomas G, et al. Effect of screeningon oral cancer mortality in Kerala, India: A cluster-randomisedcontrolled trial. 2005;365(9475):1927-1933.

9. Allgar VL, Neal RD. Socio demographic factors and delays in thediagnosis of six cancers: Analysis of data from the 'National Survey ofNHS Patients: cancer. The British Journal of Cancer. 2005;92(11):1971 -1975 .

10. Diamandis EP. Tumour markers: Past, present, and future, Tumourmarkers: Physiology, pathobiology, technology, and clinicalapplications.2002:3-8.
11. Sokoll L, Chan DW. Clinical chemistry: Tumour markers. ClinicalOncology. 2004;3:1-2.

12. Marella S. Prognostic and predictive markers in early detection of different types of cancers for selected organ sites. 2013;8:5-42.

13. Balan JJ, Rao RS, Premalatha BR, Patil S. Analysis of tumour marker CA 125 in saliva of normal and oral squamous cell carcinoma patients: a comparative study. 2012;13(5):671-5.

14. Ferlay J, Bray F, Pisani P, Parkin DM. GLOBACON 2000, cancerincidence, mortality and prevalence worldwide.2001;1:13-14.

15. Peacock S, Pogrel A, Schmidt BL. Exploring the reasons for delay intreatment of oral cancer. 2008;139:1346-52.

16. Gandolfo S, Pentenero M, Broccoletti R, Pagano M, Carrozzo M,Scully C. Toluidine blue uptake in potentially malignant oral lesions invivo: Clinical and histological assessment. 2006;42:89-95.

17. O'Brien TJ, Beard JB, Underwood L, Dennis RA, Santin $A D$, York L: The CA 125 gene: an extracellular superstructure dominated by repeat sequences. 2001; 22:348-366.

18. Yin BW, Lloyd KO. Molecular cloning of the ca125 ovarian cancer antigen identification as a new mucin. 2001;276:27371-27375.

19. Rump A, Morikawa Y, Tanaka M, Minami S, Umesaki $\mathrm{N}$, Takeuchi M, Miyajima A: Binding of ovarian cancer antigen CA125/MUC16 to mesothelin mediates cell adhesion. 2004;279:9190-9198.

20. Hattrup CL, Gendler SJ: Structure and function of the cell surface (Tethered) Mucins. 2007;70:431457.

21. Comamala M, Pinard M, Theriault C, Matte I, Albert $A$, Boivin $M$, et al. Down regulation of cell surface CA125/MUC16 induces epithelial-to-mesenchymal transition and restores EGFR signalling in $\mathrm{NIH}$ : OVCAR3 ovarian carcinoma cells. 2011;104:989999.

22. Bast RC Jr, Spriggs DR. More than a biomarker: CA125 may contribute to ovarian cancer pathogenesis. 2011;121:429-430.

23. Warnakulasuriya S. Global epidemiology of oral and oropharyngeal cancer. 2009;45:309-16.

24. Agrawal R, Chauhan A, Kumar P. Spectrum of Oral Lesions in A Tertiary Care Hospital. Journal of clinical and diagnostic research. 2015;9(6):EC11. 
25. Pudasaini S, Barar R. Oral cavity lesions: A study of 21 cases. Journal of Pathology of Nepal. 2011;1:4951.

26. Yellowitz JA, Horowitz AM, Drury TF, Goodman HS. Survey of $U$. S.Dentists knowledge and opinions about oral pharyngeal cancer. 2000;131:653-661.

27. Bagan J, Sarrion G, Jimenez Y. Oral cancer: clinical features. 2010;46:414-417.

28. Shpitzer T, Bahar G, Feinmesser R, Nagler RM. A comprehensive salivary analysis for oral cancer diagnosis. 2007;133:613-7.

29. Nagler RM, Lischinsky S, Diamond E, Klein I, Reznick AZ. New insights into salivary lactate dehydrogenase of human subjects.2001;137:363-9.

30. Joshi PS, Golgire S. A study of salivary lactate dehydrogenase isoenzyme levels in patients with oral leukoplakia and squamous cell carcinoma by gel electrophoresis method. Journal of oral and maxillofacial pathology. 2014 Sep;18(Suppl 1):S39.

31. Shpitzer T, Hamzany Y, Bahar G, Feinmesser R, Savulescu D, Borovoi I, et al. Salivary analysis of oral cancer biomarkers. 2009;101:1194-8.

32. Shetty SR, Chadha R, Babu S, Kumari S, Bhat S, Achalli $S$. Salivary lactate dehydrogenase levels in oral leukoplakia and oral squamous cell carcinoma: A biochemical and clinicopathological study. 2012;8:123-5.

33. Mohammed, Riham Abdelraouf Hyder. Salivary CA125: A Tumour Marker for Oral Squamous Cell Carcinoma (Doctoral dissertation, University of Khartoum). 2016;37:11Z.

34. Geng XF, Du M, Han JX, Zhang M, Tang XF, Xing RD. Saliva CA125 and TPS levels in patients with oral squamous cell carcinoma. The International journal of biological markers. 2013;28(2):216-20.

How to Cite this article: Yadav Shweta, Deherkar JA, Sangle AR, Chandorkar SS. Utility of salivary ca-125 and LDH as a tumor marker in oral malignancy. Int. j. clin. biomed. res. 2018;4(3): 65-69. 